\title{
THE FUTURE DESIGN DIRECTION OF SMART CLOTHING DEVELOPMENT
}

Busayawan Ariyatum, Ray Holland and David Harrison

Brunel University

\begin{abstract}
Literature indicates that Smart Clothing applications, the next generation of clothing and electronic products, have been struggling to enter the mass market because the consumers' latent needs have not been recognised. Moreover, the design direction of Smart Clothes remains unclear and unfocused. Nevertheless, a clear design direction is necessary for all product development. Therefore, this research aims to identify the design directions of the emerging Smart Clothes industry by conducting a questionnaire survey and focus groups with its major design contributors. The results reveal that the current strategy of embedding a wide range of electronic functions in a garment is not suitable. This is primarily because it does not match the users' requirements, purchasing criteria and lifestyle. The results highlight the respondents' preference for personal healthcare and sportswear applications that suit their lifestyle, are aesthetically attractive, and provide a practical function.
\end{abstract}

\section{Introduction}

Smart Clothing, one branch of Wearable Computers, is defined as all clothes made with intelligent textiles. Experts agree that 'intelligent' or 'smart' means an ability to sense stimuli from the environment, and then react or adapt behaviour to the circumstances (Baurley, 2003). According to the manner of reaction, smart textiles can be categorised into three groups: passive smart, active smart and very smart (Zhang and Tao, 2001; Van Langenhove and Hertleer, 2003). Passive smart textiles can only sense stimuli from the environment; active smart textiles can sense and react accordingly; very smart textiles can sense, react and adapt themselves to the environmental conditions. In most cases, Smart Clothes are designed to sense user requirements and environmental contexts, and provide appropriate service at the right time and place accordingly with minimum effort required from the users to operate (Marzano, 2000). In this research, Smart Clothing only refers to garments and fashion accessories that contain intelligent functions based on electronic 
technologies. Smart Clothes and Wearable Computers bring a large number of product opportunities; as Venture Development Corporation estimates that it will grow more than 50\% each year through to 2006 and its shipment will reach 563 million dollars in 2006 (Broersma, 2002). Nevertheless, this market research emphasises that the true potential of Smart Clothing can only be reached if improvements are made in consumer-based products. Although great deal of improvements are made in terms of technical aspects, Smart Clothes are struggling to gain social acceptance because they fail to follow the norms of the social interaction (Edwards, 2003). In order to improve a design process, Krose (2002) stresses that it is unavoidable to study an outcome of the process or a product and its nature. However, Uotila, et al (2003) note that Smart Clothing is an entirely new product and the users' needs have not been realised. Since the design direction remains unclear, it is difficult to improve product development and commercialisation. This situation expresses a pressing need for a clear design approach and better understanding of the consumers. Thus, this research aims to identify future directions in the design approach to Smart Clothing that match user profile and lifestyle. Since users are largely unaware of Smart Clothing products, the investigation focuses on their lifestyle and vision of the future. In addition, the purchasing criteria of the related fields, e.g. electronic and apparel goods are examined.

\section{Background Research}

The research structure reported for this paper is based on the findings of the previous investigations, namely a literature review (see Ariyatum and Holland, 2003) and in-depth interviews with key developers within the Smart Clothing field (see Ariyatum, Holland and Harrison, 2004). The results of the previous studies are briefly summarised below.

\section{Result of Literature Review}

The literature review was conducted to identify the design evolution and trends in Smart Clothing development. Information as well as images of the current research and development projects from different teams were collected and put on a timeline chronologically (see figure 1). Results from the comparison and analysis conducted with the current projects reveal that the design evolution was divided into three periods. 
1. In the first period, 1980 s to 1997 , the design approach was regarded as technologydriven, since most research and developments focused on Wearable Computing and applications of advanced technologies (see, for example, Mann, 1996; Orth, Post and Cooper, 1998). For instance, Randell (2001) predicted that integrating sensing and displaying technologies could bring a lot of opportunities to textile manufacturers. Thus, the researcher and his team developed 'CyberJacket', which integrated location sensors (GPS), displays, etc, to demonstrate the possibilities. Nevertheless, this prediction was based on the trends of miniaturisation of electronic devices not consumer requirements. Whether people carry electronic devices around means they want these devices to be part of their clothes and operate unobtrusively without the user being conscious of it is debatable. Furthermore, the inputs from fashion design and business were neglected. Therefore, the products were more 'portable' rather than 'wearable', for example, MIT’s wearable computer (O’Mahony, 2002).

2. In the second period, 1998 to 2000 , the awareness and involvement of the fashion and textile sector significantly rose. Consequently, the number of the collaborative projects between electronic and fashion fields rapidly increased, for example, the Cyberia project (Rantanen, et al, 2000). Moreover, experts in textile and clothing started to create their own research and development (Braddock and O'Mahony, 1998). For instance, the Haute Couture designer, Alexandra Fede, worked with Du Pont and Mitsubishi Materials Corporations to develop the collections incorporating advanced technologies. Although the applications became more wearable, most outcomes were still prototype garments, as the technologies were underdeveloped, e.g. Philips and Levi's ICD+ jacket (Meoli and May-Plumlee, 2002), and SCOTT eVast (Forman, 2001). Besides, product concepts, e.g. having optical fibre screen on clothes (see Gould, 2003; France Telecom, 2003), did not match requirements of the mass market.

3. In the third period, 2001 to 2004, the number of Smart Clothes available in the market increased dramatically, e.g. The North Face's MET5 ${ }^{\mathrm{TM}}$ jacket (Ward, 2001), Adidas's smart shoes (Momphard, 2004) and GapKid's sweatshirts with embedded FM radio 
(CNN, 2004). Multidisciplinary approach and user-centred design are widely adopted by most development teams. Furthermore, the boundary of the applications expanded into new areas. For example, Dodson (2003) reports that Northwest Airlines in the US give their staff a wearable computer to reduce the time for the check-in.

GapKid's Hoodio (a sweatshirt with machine-washable FM radio embedded) was launched in November 2004 Adidas introduced 'Adidas 1' - self-adapting shoes in May 2004

i-WEAR Fashion Show in Paris (05/11/03) featured Alexandra Fede's high tech collections Nokia presented the new wearable range in 2003 and planned to launched the products in $1^{\text {st }}$ quarter of 2004 ',

Tokyo University's Transparent Clothes was published on BBC News website in February 2003

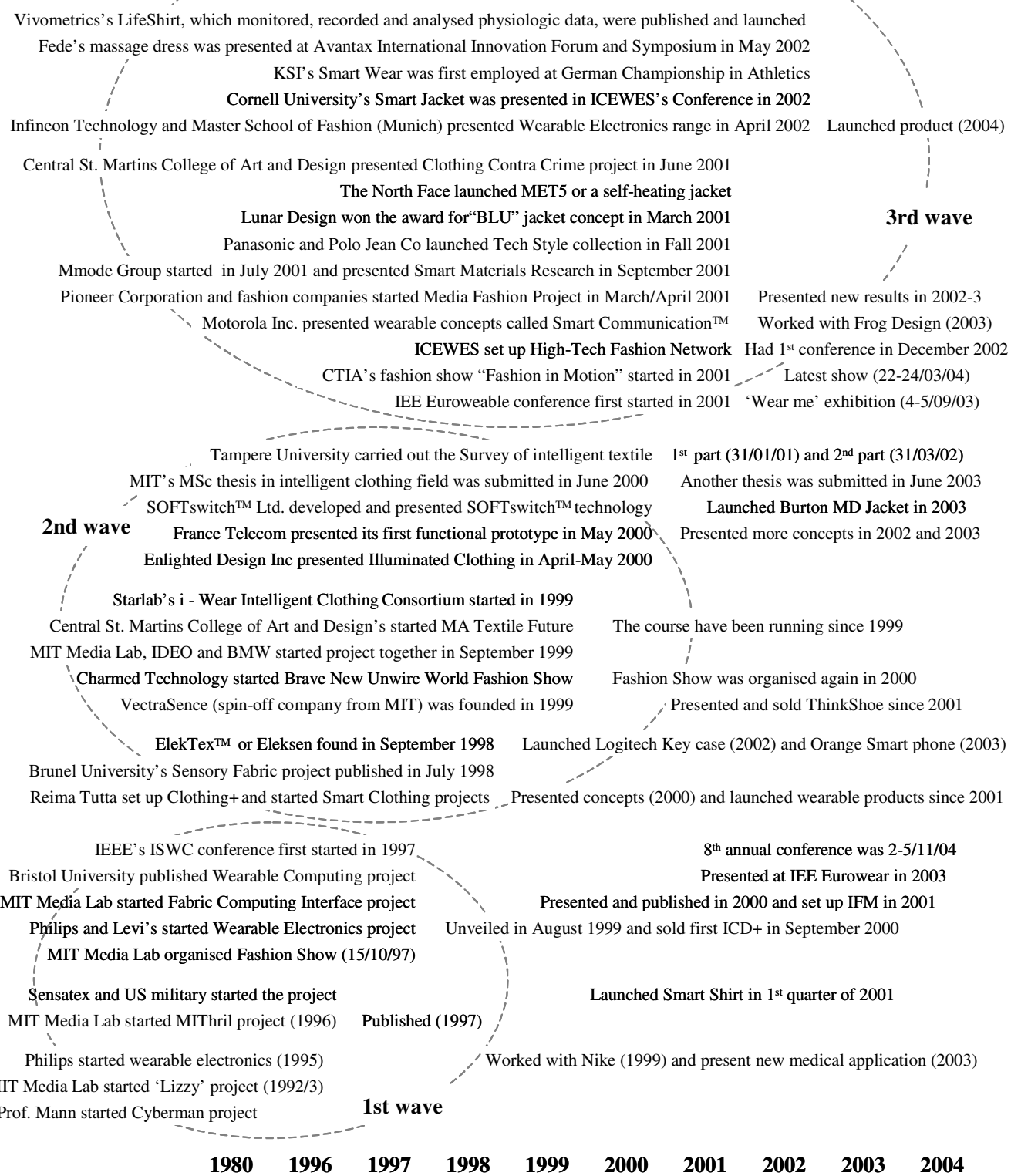

Figure 1: Diagram demonstrating the evolution of the Smart Clothing's design direction

Smart Clothes have become more wearable due to the user-centred approach. Moreover, the current applications are developed for specific tasks such as health monitoring (see 
Marculescu, et al, 2003; Dunne, Ashdown and McDonald, 2002 for example), rather than to adhere to every day-to-day activity like the early applications did. As a result, the target users of particular applications have become clearer. A number of Smart Clothes have proved to be feasible and are already available in the market, e.g. Philips' ICD+ jacket (Philips, 2000) and VivoMetrics's Lifeshirt (Momphard, 2004). Nevertheless, these products are unable to attract the mass market, since Smart Clothes are still about portability rather than electronics being fully integrated (Lee and Stead, 2001). In order to make the applications more commercial, the researchers suggest that Smart Clothing developers need to address usability, wearability, and user's requirements. Considering a few extra functions that Smart Clothes offers, the products are regarded very expensive. For example, Ward (2001, p.33) describes The North Face’s MET5: 'the jacket will retail in the UK at £380. Combined with relatively small scale production of the new material, uptake of the new garment is unlikely to be widespread.' This situation has not only been caused by the unsolved technical problems, but also by the lack of a strategic approach and design direction, as the developers failed to recognise what function is desirable for the users.

\section{Results of the In-depth Interviews}

A semi-structured interview was chosen to investigate how the key developers anticipated the future of Smart Clothes because this method allowed the respondents to express and discuss the interviewed subjects openly (Flick, 2002). In this way, the interviews remained focused and directive as well as explorative, especially about social, cultural and organisational issues. In this research, the interviewed subjects focused on current design approaches, problems that they encountered and what would be an appropriate design direction which could solve or avoid existing problems. The interviewees included a design manager, a smart clothing designer, a product designer, a fashion designer, a technical textile designer, a technical textile technician, an electronic engineer and a trend researcher. These interviewees were selected due to their commitment to taking future design directions on board. Most of them were experts in this field and had experience of working in Smart Clothing development teams for at least three years. Furthermore, they were either involved in major collaborative projects between the apparel and electronic industries, researched 
and published several academic papers, or developed applications that were available in the market. Certain interviewees were considered potential developers, as their expertise, e.g. future trend forecasting, was prospectively required in the future. The responses were tape recorded, transcribed and analysed in order to identify how the key developers anticipated the future lifestyle and design direction. A summary of the design directions recommended by the key disciplines is presented below:

1. Many interviewees suggested that Smart Clothing applications should take the design approach of Functional Clothing because its nature is similar to that of Smart Clothing. For instance, Functional Clothing has a long lifecycle. Long lifecycle is crucial for Smart Clothing applications, as technologies take a long time to develop and test. In this case, Functional Clothing is a garment designed to serve specific purposes, e.g. garments for extreme conditions and military or fire fighters' uniforms.

2. Most interviewees pointed out that the design direction for mass market had moved towards the area of physical monitoring, sportswear and personal healthcare. This change not only helps expand the market to the new target groups, children and the elderly, but also focuses the design approach. Moreover, these new areas were more innovative and experimental which matched the nature of Smart Clothing.

3. Several developers agreed that social acceptance was an important factor. Although Smart Clothes need not be fashionable, they should perform all the basic functions that ordinary garments do. Some interviewees stressed that the electronic function should be discrete and invisible. Further, it should be a wearable item, since it is easier for the users to accept. However, most experts expressed that changing the user's perception was the biggest challenge. Moreover, Smart Clothes should have a simple design. This way the products have a long lifecycle regardless of any changes in fashion trends.

\section{Summary of Background Research}

The key issues identified from the previous research are summarised below:

1. The background research reveals that the developers are currently interested in the area of physical monitoring, sportswear and personal healthcare. However, whether these design directions fit the users' requirements and their lifestyle needs to be confirmed. 
2. The design directions identified from the previous research are still too broad for implementation. As a result, these directions require a further investigation. Examining contributions from Smart Clothing's major design contributors, namely product and fashion designers, would make these directions more specific and focused.

3. Although the literature research and the interviews indicated that the design direction has moved towards the user-centred approach, the target market has not been clearly defined. Consequently, the user requirements cannot be specified. Recently, most developers aim to create functional applications. Nevertheless, the biggest question is 'what function is actually expected by the users from Smart Clothes?' Therefore, the profile of potential users and their requirements must be clarified and addressed.

\section{Aims}

In light of the key issues illustrated above, this research focused on three issues:

1. To develop a profile for one potential target group of Smart Clothing application

2. To discover a vision of the future lifestyle for this potential target group

3. To identify a design direction of Smart Clothing application for this specific group

\section{Overview of Research Method}

The research structure is relatively similar to the 'Delphi technique', which was developed to obtain a consensus view on a given subject. Baxter (1995) summarises that, in the Delphi technique, firstly, structured questionnaires are developed and sent to selected participants or experts in a particular area, in order to gain a broad ranges of ideas. The responses from the first round are collected and summarised to form a basis for the second questionnaires, which aim clarify or expand the issues, identify areas of agreement and disagreement, etc. In most cases, the participants are asked to vote on a specific proposal. The feedbacks from the second round are summarised and sent back in the form of the third questionnaires. In this way, the results of the third round are regarded as a consensus opinion of the participants.

However, this research aimed to identify areas of agreement of all stakeholders, including, not only existing Smart Clothing developers, but also potential users and potential 
developers. Thus, firstly, the literature review and interviews with the key developers were employed to explore a broad range of possibilities for the Smart Clothing design direction. The responses from the interviews were collected and analysed to form a questionnaire, which clarifies whether the end users agreed with the key developers and establishes a user profile and purchasing criteria. As a result, this questionnaire survey investigated the user's personality, consumer's requirements, perception of related products and their visions of future lifestyle and test certain ideas suggested by the interviewees and literature.

Secondly, focus groups were conducted with the main design contributors of Smart Clothing: the fashion and product designers. This focus group was an extended study of the previous research; thus, its structure and questions were developed based on the findings of the interviews and questionnaires. Nonetheless, its topics of discussion were more specific, as the focus group aimed to discover not only precise design directions, but also how these approaches could be implemented. Although, the interviewees also included product and fashion designers, the criteria to select the interviewees and focus group respondents, as well as the outcomes expected from these two researches, were different. While the interviewees must have some work experience in Smart Clothing research and development or related fields, the focus group respondents needed not to have any experience or be aware of Smart Clothing. In this way, the researcher was able to gain the insightful opinions from the 'insiders' and fresh ideas of 'outsiders'. Different perspectives from three groups of stakeholders were analysed in order to identify the consensus of opinions (see figure 2).

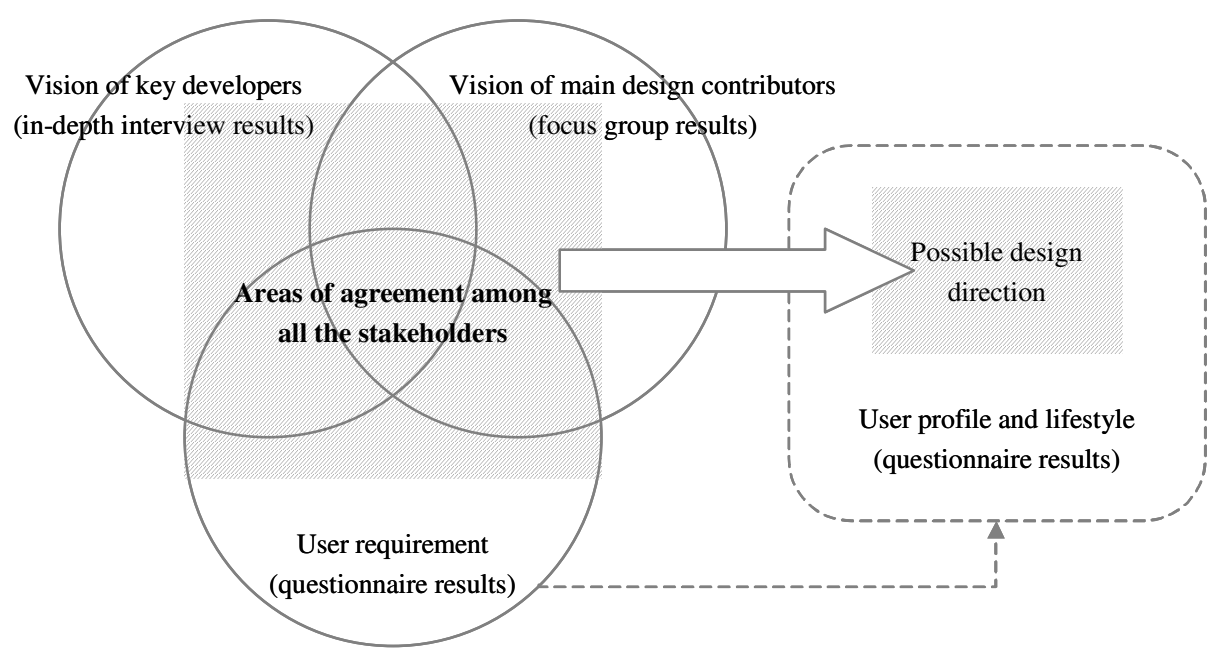

Figure 2 Diagram demonstrating how the results from each primary research are integrated 
The consensus views shared among all the stakeholders are deduced and described in detail, as they represent promising design directions with potential market and feasible production. The design directions obtained from the interviewees and focus group respondents must match the user's profile and requirements identified from the questionnaire survey. In this manner, the findings from quantitative and qualitative research are integrated.

\section{Questionnaire}

Aims: The questionnaire aims to identify three key issues:

1. Gaining an understanding about consumer perceptions, personality and lifestyle of the specific group in order to produce a profile of Smart Clothing potential users.

2. Identifying purchasing criteria of electronic devices, fashion clothes and sportswear products and finding out if there is any relationship between these criteria. Sportswear products, a combination of fashionable design, serious function and high technology, were chosen in order to investigate whether their position is appropriate for Smart Clothes. Moreover, Smart Clothing developers are interested in sportswear, as many interviewees recommended carrying out user research with this product.

3. Obtaining consumer visions of future lifestyles and comparing with the vision of the developers in order to check if the existing scenario is still appropriate for this group.

Hypotheses: In this case, there were two experimental predictions. Firstly, it was predicted (two-tailed prediction) that there would be an association between product categories and purchasing criteria of the consumers. Secondly, it was predicted (two-tailed prediction) that there would be a significant difference between the purchasing criteria of three different products. In this research, there was only one independent variable: product categories.

Participants: Potential users of existing Smart Clothes, identified by the developers, were chosen as the targets of this questionnaire survey because of two main reasons. Firstly, this research could bring about better understanding of the target users in terms of personality, desirable lifestyle, purchasing criteria of related products, etc, which could help the developers improve their design and commercialisation of existing applications. Secondly, 
the literature review and the interviews revealed that these existing targets still had strong potential as an early adopter of Smart Clothing application. The potential users described by Smart Clothing developers were rather broad, as they included several groups of people with different demographic background, e.g. elderly people, soldiers, intensive-care patients, etc. In this case, the most common targets usually described as young and designconscious individuals who were interested in advanced technology (Van Heerden, Mama and Eves, 2000; LUNAR Design, 2001; Mori, 2002) were chosen as an example. The respondents were randomly selected from design students at Brunel and other London universities (age between 16-35), since they were interested in design and new technologies and often exposed to innovative products. The proportion of respondents is shown below.

Table I: Age groups of the respondents

\begin{tabular}{|lccccc|}
\hline Age group & Under 20 & $\mathbf{2 1 - 2 5}$ & $\mathbf{2 6 - 3 0}$ & $\mathbf{3 1 - 3 5}$ & Total \\
\hline Number of respondents & 15 & 28 & 18 & 9 & 70 \\
Percentage & $21.4 \%$ & $40.0 \%$ & $25.7 \%$ & $12.9 \%$ & 100 \\
\hline
\end{tabular}

Material: The questionnaire was designed according to the three key issues it addressed:

1. Profile of the correspondents: This set of questions included demographic and personal information, such as personality, personal interests, desirable products and role models. In this case, eight personalities, used as alternatives, were identified by the developers.

2. Purchasing criteria of electronic, apparel and sportswear products: Eight leading brands of mobile phones, high-street fashion retailers and sport shoes were chosen to represent these three categories because the respondents are familiar with these products. In this case, the high-street fashion retailers selected owned both male and female ranges; therefore, the same questionnaire could be used with both genders. The respondents were questioned about their favourite brand, the frequency of their purchasing, and the main reason that they chose or rejected a particular brand/model.

3. Vision of the future: Eight scenarios of future lifestyles were selected from:

- The key trends identified by leading research consultancies. For instance, Seymour Powell Foresight (2003) produces the 'Trends Overview' including all the major 
trends, such as health consciousness and risk consciousness.

- The visions of leading electronic companies. For example, Samsung envisages that, in the future, data can be automatically transferred from one device to another without the user's awareness (An, et al, 2003). This way, a personal data assistant updates appointments and address books daily by communicating with a computer.

- The opportunities identified by the developers, e.g. crime prevention (Lee and Stead, 2001) and pollution protection (Van Heerden, Mama and Eves, 2000).

- The future scenarios developed by researchers in academic institutes. For example, Pantzar (2000) investigates future consumption and illustrates many scenarios, e.g. people will learn, work and shop at homes, which have intelligent systems, or become computer-dependent and are always connected to entertainment devices.

The scenarios that were shared by many sources were used to form the alternatives for the respondents to choose in order to see how the consumers anticipate the future.

Most of the questions were in multiple-choice form, and images were used wherever they were required to make each multiple choice as comprehensible as possible (see appendix). The results were sorted and analysed with computer software, SPSS, which is specialised in statistical calculation. Finally, conclusions about consumer profile, user requirements, purchasing criteria and the consumer's vision of future lifestyle can be deduced.

\section{Focus group}

This method was selected because of its strength in 1) exploration and discovery, 2) context and depth, and 3) interpretation. Morgan (1998) explains that focus groups provide an insight into topics that are poorly understood. Moreover, the author states that a process of 'sharing and comparing' information among the participants from similar backgrounds in a group discussion produces large amounts of concentrated data about a chosen topic, which, in this case, are what the major design contributors think of Smart Clothes.

Aim: The aim of the focus group is to obtain personal opinions, from the major design contributors of Smart Clothing development, about appropriate design directions of future applications, and how these design approaches can be implemented. 
Participants: In this research, there are two focus groups. The first group was conducted with five product designers and the second one was carried out with five fashion designers. The samples of each group were a mixture of three design researchers and two professional designers. Thus, the researcher was able to gain both academic and industrial viewpoints.

Procedure: Before starting a group discussion, the researcher briefly introduced the subject area, Smart Clothing. Next, the researcher explained the purpose of the focus group and discussion topics. The main topic was: If you are a lead designer of a Smart Clothing development project, which design direction would you take and why? After the discussion amongst the participants about the topic, the researcher summarised all the key issues and agreements made. Furthermore, the researcher made sure that each design direction suggested by the participants was clearly explained with an example of its implementation. All discussions were recorded and transcribed with a view to analysis in the next stage.

\section{Analysis}

There are two types of analytical methods employed in this research. Firstly, quantitative analysis was employed to examine questionnaire findings and this method consisted of:

1. Sorting the results into different tables and checking frequencies of the data in order to identify which alternative achieved the highest score for each question.

2. Studying the data about the target's personality in order to generate a new user profile and then comparing it to an existing one created by Smart Clothing developers.

3. Identifying key factors effecting the purchasing criteria of three different products by listing three alternatives that achieved the highest score in each category.

4. Discovering relationships between purchasing criteria and product types through the use of statistical non-parametric tests. Firstly, a chi-square test assessed the (two-tailed) prediction that there would be an association between product types and purchasing criteria. Secondly, a wilcoxon test assessed another (two-tail) prediction that there would be a significant difference between the purchasing criteria of different products.

5. Reviewing the data to find out the consumers' vision of future lifestyle and comparing it to the existing scenario to identify similarities and contrast differences. 
Secondly, a grounded theory analysis was carried out to interpret responses from the focus groups. Firstly, the notes and transcripts were examined several times in order to familiarise and further comprehend the responses. Besides, particular attention was made to distinguish the different tone of the respondents' voices. For example, highlighting was used for the information that a respondent frequently repeated and emphasised. Through the coding procedure, the information gathered was deconstructed into categories to extrapolate the key issues, which were then reconstructed to provide a new meaning to the information.

\section{Research Findings and Discussion}

The findings can be divided into three groups according to the aims: 1) consumer profile and requirements, 2) future lifestyle scenario and 3) new design direction. The first two groups were developed based on the questionnaire findings, while the last category was created based on focus group results supported by the information from the interviews.

\section{User Profile and Requirements}

The findings from the questionnaires reveal that the personality of this group is different from what some developers expected. The target audiences did not perceive themselves as 'high-tech' as described by the developers. For example, the highest score in terms of selfperceived personality is sporty and health-concerned (18.6\%), followed by practical and price-concerned $(17.1 \%)$, and fashion-conscious $(14.3 \%)$. None of the respondents expressed an interest in people with 'high-tech' lifestyle, as their role models are either celebrities in the entertainment business (31.4\%), top athletes (20\%) or successful professionals, such as famous designers, successful businessmen/women and writers (20\%). Moreover, the role models are chosen either due to their personality (31.4\%), success $(15.7 \%)$ or physical appearance $(11.4 \%)$. Although the high-tech gadgets appealed to the respondents, electronic devices did not come first in the list of favourite objects. Fashion items received the top score $(24.3 \%)$, followed by personal electronic devices $(21.4 \%)$ and work related products $(18.6 \%)$. Nonetheless, these objects were chosen either because of their usefulness and practical function $(37.1 \%)$, personal values $(20 \%)$, or a unique design and beauty of the product (18.6\%), and not high-tech features. 
A chi-square test assessed the two-tailed prediction, that there would be an association between the type of products (a mobile phone, a fashion garment and sport shoes) and purchasing criteria, to be significant $\left(\mathrm{X}^{2}=59.65\right.$, $\left.\mathrm{df}=14 ; \mathrm{P}<0.05\right)$. Hence, there was a significant association between the product type and the reason why it was purchased. A breaking down of the different purchasing criteria to assess which criteria was dictating purchase illustrated that 'good design' influenced the purchase of all products (see Table II), for example $31.4 \%$ of respondents selected a mobile phone due to its 'good design' and $44.3 \%$ of respondents declared that 'good design' affected the purchase of sport shoes. However, there were some differences in the way people perceive, purchase and use different products, especially electronic devices and clothes (see figure 3 - 4). For instance, the fashion clothes are purchased frequently compared to electronic devices (see Table III) and they are selected based on emotional values e.g. matching the user's lifestyle $(51.3 \%)$ and attractive design (21.4\%). In contrast, many consumers still purchased an electronic device due to its practical functions $(17.1 \%)$ and provision of various features $(22.9 \%)$.

Table II: Desirable factors affecting consumer's purchasing

\begin{tabular}{|l|rr|rr|rr|}
\hline Criteria & \multicolumn{2}{|c|}{ Mobile phone } & Fashion garment & \multicolumn{2}{|c|}{ Sport shoes } \\
\hline Good design & 22 & $31.4 \%$ & 15 & $21.4 \%$ & 31 & $44.3 \%$ \\
Practicality & 12 & $17.1 \%$ & 2 & $2.9 \%$ & 11 & $15.7 \%$ \\
Newness/Trendiness & 1 & $1.4 \%$ & 2 & $2.9 \%$ & 0 & $0.0 \%$ \\
Reliability/High quality & 4 & $5.7 \%$ & 4 & $5.7 \%$ & 8 & $11.4 \%$ \\
Match your lifestyle & 8 & $11.4 \%$ & 36 & $51.4 \%$ & 7 & $10.0 \%$ \\
Value for money & 5 & $7.1 \%$ & 4 & $5.7 \%$ & 7 & $10.0 \%$ \\
Famous brand & 0 & $0.0 \%$ & 0 & $0.0 \%$ & 0 & $0.0 \%$ \\
Varied features/Multipurpose & 16 & $22.9 \%$ & 6 & $8.6 \%$ & 4 & $5.7 \%$ \\
Other & 2 & $2.9 \%$ & 1 & $1.4 \%$ & 2 & $2.9 \%$ \\
\hline
\end{tabular}

Table III: Comparison of the frequencies of purchasing

\begin{tabular}{|lr|lr|}
\hline \multicolumn{2}{|l|}{ Frequency of purchasing mobile phones } & \multicolumn{2}{|l|}{ Frequency of purchasing clothes } \\
\hline When the old one is broken & $39.2 \%$ & Once a month & $33.9 \%$ \\
Once every year & $30.4 \%$ & Every two-three weeks & $19.6 \%$ \\
Every two-three years & $23.2 \%$ & Every two-three months & $12.5 \%$ \\
\hline
\end{tabular}


$\square$ Good design $\square$ Facticality $\square$ New ness $\square$ Reliability/High quality $\square$ Match lifestyle $\square$ Value for money $\square$ Famous brand $\square$ Muttipurpose $\square$ Other

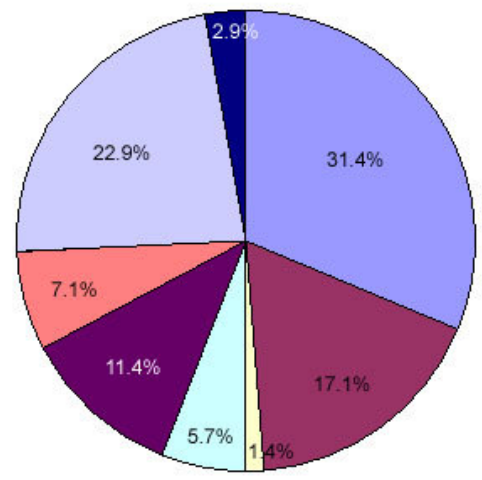

Purchasing criteria of a mobile phone

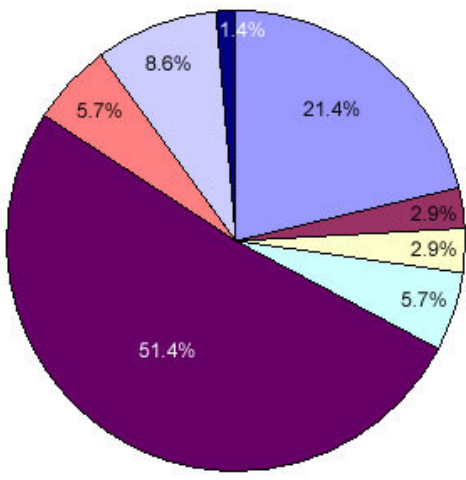

Purchasing criteria of a fashion garment

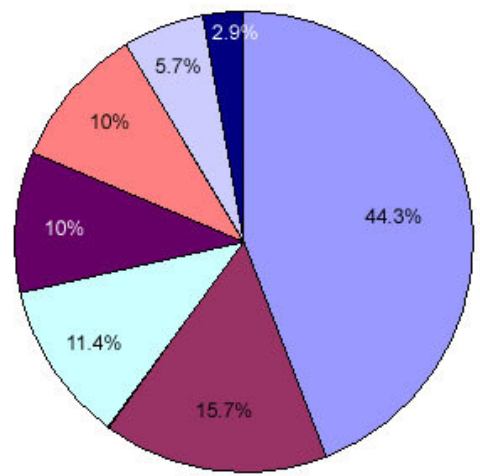

Purchasing criteria of sport shoes

Figure 3 Pie charts illustrating purchasing criteria of three different products

Undesirable factors were also investigated, since certain factors that had a small impact on purchasing could have a great influence on rejecting a particular product (see figure 3 and 4). For instance, only $5.7 \%$ of the respondents reported that 'high quality' and 'value for money' influenced the purchase of a fashion garment (see table II). However, $15.7 \%$ of the respondents declared that they would reject a fashion garment if it had an unreasonable price and $18.7 \%$ of respondents stated that low quality influenced their decision to reject a particular brand (see table IV). Furthermore, the factors that had no effect on sport shoes' purchasing criteria, such as newness and famous brand, had some impact on the decision to reject particular shoes. For example, $7.1 \%$ of respondents affirmed that they would reject sport shoes if they were old-fashioned and $4.3 \%$ of respondents proclaimed they would not buy no-named sport shoes (see table IV). The findings indicate that both desirable and undesirable factors must be addressed when developing or commercialising a product.

Table IV: Undesirable factors affecting consumer's purchasing

\begin{tabular}{|l|rr|rr|rr|}
\hline Criteria & \multicolumn{2}{|c|}{ Mobile phone } & \multicolumn{2}{|c|}{ Fashion garment } & \multicolumn{2}{|c|}{ Sport shoes } \\
\hline Unattractive design & 34 & $48.6 \%$ & 23 & $32.9 \%$ & 25 & $35.7 \%$ \\
Impracticality & 15 & $21.4 \%$ & 2 & $2.9 \%$ & 5 & $7.1 \%$ \\
Dated or old-fashioned & 6 & $8.6 \%$ & 1 & $1.4 \%$ & 5 & $7.1 \%$ \\
Low quality & 0 & $0.0 \%$ & 13 & $18.5 \%$ & 13 & $18.5 \%$ \\
Do not match your lifestyle & 3 & $4.3 \%$ & 16 & $22.9 \%$ & 4 & $5.7 \%$ \\
Unreasonable price & 8 & $11.4 \%$ & 11 & $15.7 \%$ & 13 & $18.5 \%$ \\
\hline
\end{tabular}




\begin{tabular}{|l|cr|rr|cr|}
\hline Criteria & \multicolumn{2}{|c|}{ Mobile phone } & \multicolumn{2}{|c|}{ Fashion garment } & \multicolumn{2}{|c|}{ Sport shoes } \\
\hline No-name brand & 0 & $0.0 \%$ & 0 & $0.0 \%$ & 3 & $4.3 \%$ \\
Limited function & 3 & $4.3 \%$ & 3 & $4.3 \%$ & 1 & $1.4 \%$ \\
Other & 1 & $1.4 \%$ & 1 & $1.4 \%$ & 1 & $1.4 \%$ \\
\hline
\end{tabular}

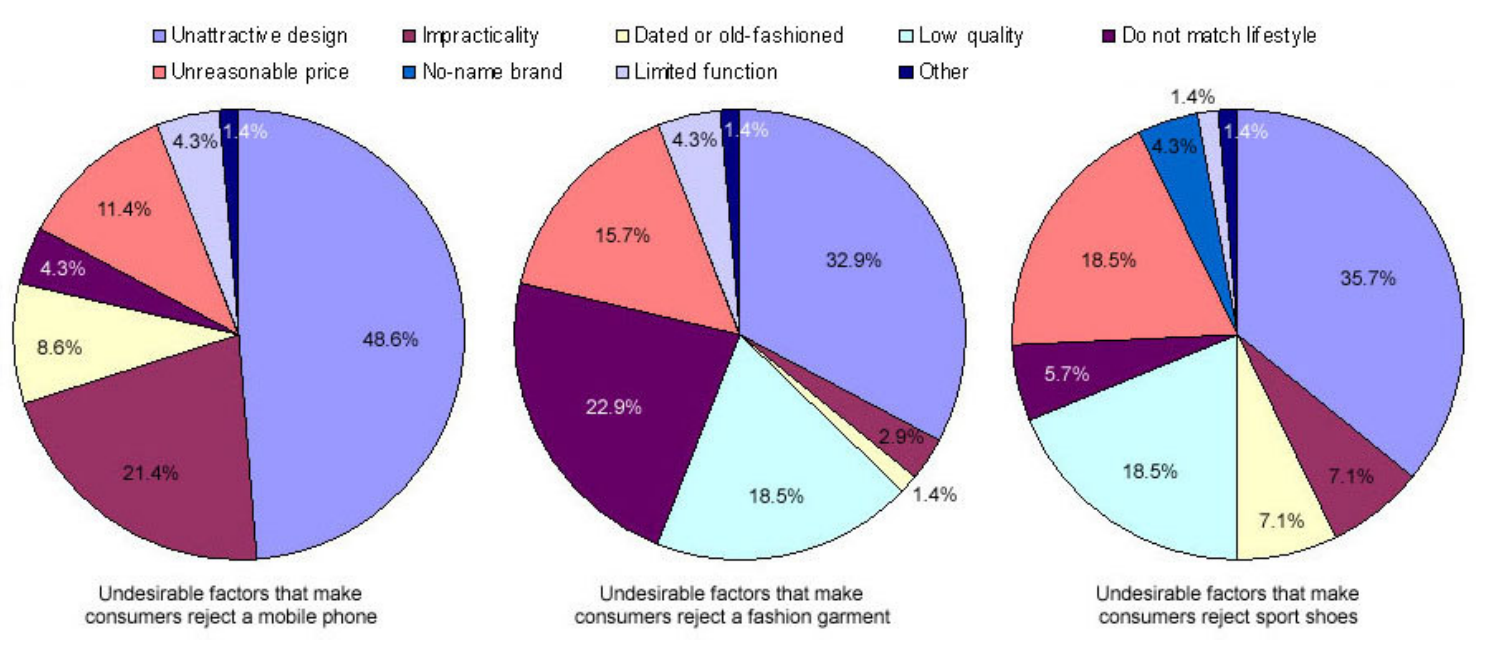

Figure 4 Pie charts demonstrating undesirable factors influencing purchasing behaviour

A wilcoxon test was carried out to assess the difference between the two product types (a mobile phone - a fashion garment; a fashion garment - sport shoes; a mobile phone - sport shoes). The result indicated that there was a significant difference between the purchasing criteria of a mobile phone and a fashion garment $(\mathrm{z}=0.92 ; \mathrm{p}<0.05)$, a fashion garment and sport shoes $(\mathrm{z}=3.29 ; \mathrm{p}<0.05)$ and a mobile phone and sport shoes $(\mathrm{z}=2.37$; $<<0.05)$.

Therefore, it can be conclude that there was a significant difference between the purchasing criteria of different product types. The difference between the purchasing criteria of different products illustrates a potential problem of a hybrid product like Smart Clothing. Whilst the clothing parts of Smart Clothes may be perceived and selected according to a fashion garment's criteria, such as matching lifestyle and attractive design, the electronic parts of Smart Clothing application may be perceived and chosen due to the number of features and practicality. In addition, 33.9\% the respondents reported that they purchased new garments every month, while $32.9 \%$ of respondents stated that they would not buy a new mobile phone until the old one broke down. Nevertheless, there was a possibility to reconcile the difference, since the key factors influence the purchase of these three products were similar (see figure 3 and 4), such as good design and matching users' lifestyle. 
According to the pie charts in figure 3 and 4, it can be seen that sportswear's purchasing criteria was a combination of those of an electronic device and a fashion garment, as it addressed factors that influenced the purchase of a fashion garment, namely good design, high quality and matching users' lifestyle, as well as factors that affected the purchase of an electronic device, such as practicality. Moreover, the favourite choice of each category was a combination of fashionable design, lifestyle matching and practical function. For example a Nokia mobile phone and Nike shoes (see table V). Noticeably, the respondents' preference of fashionable design and practicality was applied across different product types.

Table V: Users' preference three different products

\begin{tabular}{|l|cc|l|cl|l|l|l|}
\hline \multicolumn{4}{|c|}{ Mobile phone } & \multicolumn{3}{c|}{ Fashion garment } & \multicolumn{3}{c|}{ Sport shoes } \\
\hline Nokia & $\mathbf{3 4}$ & $\mathbf{4 8 . 6 \%}$ & Gap & $\mathbf{1 8}$ & $\mathbf{2 5 . 7 \%}$ & Nike & $\mathbf{4 2}$ & $\mathbf{6 0 . 0} \%$ \\
Sony Ericsson & 18 & $25.7 \%$ & Other & 13 & $18.5 \%$ & Adidas & 10 & $14.3 \%$ \\
Samsung & 8 & $11.4 \%$ & DKNY & 12 & $17.1 \%$ & Puma & 8 & $11.4 \%$ \\
Siemens & 3 & $4.3 \%$ & Topshop & 9 & $12.9 \%$ & Converse & 4 & $5.7 \%$ \\
Panasonic & 2 & $2.9 \%$ & H\&M & 9 & $12.9 \%$ & Other & 3 & $4.3 \%$ \\
Sharp & 2 & $2.9 \%$ & NEXT & 7 & $10.0 \%$ & Reebok & 1 & $1.4 \%$ \\
Other & 2 & $2.9 \%$ & Versace & 2 & $2.9 \%$ & Fila & 1 & $1.4 \%$ \\
NEC & 1 & $1.4 \%$ & M\&S & 0 & $0.0 \%$ & Mizuno & 1 & $1.4 \%$ \\
Motorola & 0 & $0.0 \%$ & Matalan & 0 & $0.0 \%$ & Ellesse & 0 & $0.0 \%$ \\
\hline
\end{tabular}

Considering these results, a spectrum of purchasing criteria was constructed (see figure 5).

'Practical function and features' at one end, and 'emotions and lifestyle' at the other end.

On this spectrum, the various products such as electronic, sportswear and fashion items were placed as a result of the questionnaire resources. Figure 5 conveys that the position of sportswear on the spectrum is probably the appropriate place for Smart Clothes, as the Smart Clothes must address practical function like electronic devices do, and attractive design and emotional values as fashion clothes do.

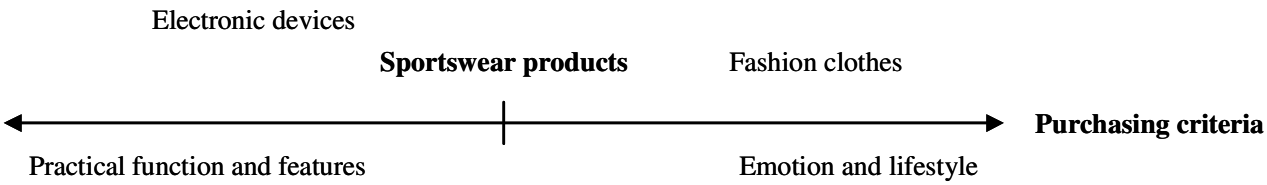

Figure 5 Spectrum of purchasing criteria demonstrating position of three different products 


\section{Vision of Future Lifestyle}

The questionnaire results reveal that the consumers' vision of future lifestyle is different from the existing scenarios created by Smart Clothing developers. From the developers' point of view, Smart Clothes should provide appropriate services at the right place and time according to the environmental context it senses without user conscious operation. The functions that the application should perform range from location sensor and navigation, entertainment, shop assistant, memory enhancement, etc. Nevertheless, the consumers are more concerned about how the product can enhance their quality of life in terms of health and well-being (44.3\%). These findings support the user profile described earlier. Only a few targets believe that future lifestyle is about artificial intelligence (2.9\%) and avant-garde design $(2.9 \%)$. In contrast, many respondents pay more attention to environmental issues (22.9\%) and how to enrich their sensory experiences (10\%). This highlights that the participants from the previous interviews correctly surmised what the popular applications and subsequent needs would be. For instance, they stated that sportswear and medical applications would be an appropriate direction for the mass market in the future.

\section{New Design Direction}

In this section, a summary of Smart Clothing's design direction, suggested by product and fashion designers, is presented. The suggestions of these two groups will be compared to find out the similarities. Similar recommendations will be drawn as a potential design direction. The ideas that are different are also useful. However, it is probably easier for development teams to start with a vision that is shared between both design contributors.

1. Design direction suggested by product designers: Due to their user-centre approach, the group preferred practical applications, such as those for the military, monitoring and medical because these products had a potential market and fit the current trend, i.e., a healthy and wellbeing lifestyle. Since product designers are always concerned about business benefits, some respondents were interested in the ideas that could be achieved with today's technologies, e.g. child monitoring applications. The group challenged the word 'Smart' and later agreed that it meant technology was invisible and function was provided only when it was needed without the user's conscious thought, which was 
similar to the Smart Clothing developers' idea. However, the user must control the technology. Moreover, social acceptance and user lifestyle must be addressed. Many respondents expressed their concerns about environmental issues, as new legislation requiring the producers to take back all their electronic components at the end of the product's life. However, integrating electronics into clothing makes disassembly difficult and costly. Until every part was made of fabric, electronic components must not be permanently fixed within the clothes. Hence, electronic functions could be customised. Customisation could ensure that the products are useful for the user and could be used for longer. They believed that the clothes would be adopted by the military long before it would become a commodity product for the general consumers.

2. Design direction suggested by fashion designers: Since marketing was important for the fashion system, many respondents suggested that Smart Clothes needed to be more commercial. As a result, its design direction must be reconsidered, as one designer said 'I will tell the group's members that maybe the direction is not about technical things at all, but how to make people really buy it.' They believed that the poor acceptance from the consumers was caused by the lack of fashionable appearance. Because the final outcome is an apparel product, Smart Clothes must be designed with fashion consideration. This meant that the product must match user requirements functionally and emotionally. Many of them agreed that technology could add values to the clothes, but it was not the main reason that made people want the garment. The group stressed that emotional values, such as providing a pleasurable feeling, were more crucial for apparel products. Technology must be simplified. If technology was not invisible, it should have an attractive appearance and become 'accessories' of the clothes, such as a button or zip. In this way, electronic function could be added or removed easily due to the user's functional and emotional requirement. Being an 'accessory' allows electronic functions to be used for longer, as the style of the clothes can be changed according to fashion trends whilst basic parts, like a button, can remain the same. However, the electronic function must be complete in itself, as it is impossible to have a 'supported system' embedded in every garment. In their opinion, an appropriate function was 
physical monitoring for sport practitioners. Nevertheless, the product could be sold purely by its aesthetics. In this case, the new expression or fashion statement must be based on intelligent textiles or electronic properties, such as decorating with light

\section{Qualitative analysis}

Open coding and axial coding procedures of a grounded theory were selected to analyse data collected from the focus groups because it specialises in qualitative content analysis (Flick 2002). Strauss and Corbin (1990, p.57) describe coding procedures as 'the operations by which data as broken down, conceptualized, and put back together in new ways. It is the central process by which the theories are built from data.' These procedures eliminate biases and assumption and generate 'a rich, tightly woven, explanatory theory that closely approximates the reality it represents' (Strauss and Corbin, 1990, p.57). Whilst the open coding is a process that identifies, conceptualises, categorises and develops the concept in terms of their properties and dimension, the axial coding was a procedure for putting data back together in new way by making connections between categories.

As a result, data were first broken down or disentangled from the transcripts. At this stage, all key words or concepts were identified, for instance, 'change direction', 'fashion values', 'main purchasing reason', 'simplifying technology', etc. The concepts or codes were review and compared with each other to ensure that similar codes share the same name. Next, all the codes were grouped into categories, and then a name that

As a result, data were first broken down or disentangled from the transcripts. At this stage, all key words or concepts were identified, for instance, 'change direction', 'fashion values', 'main purchasing reason', 'simplifying technology', etc. The concepts or codes were review and compared with each other to ensure that similar codes share the same name. Next, all the codes were grouped into categories, and then a name that represents the data in the group was chosen, for example, 'easy to add new function', 'easy to remove old function', 'change function', 'change style', 'follow trends', 'follow user's mood', etc, were grouped into a category named 'personalisation.' At the end of the open coding procedure, 
the properties of each category were labelled and dimensionalised. For instance, the 'fashion values' category contained several properties, such as 'fashion statement', 'emotional satisfaction', etc. An appropriate degree of 'fashion statement' of Smart Clothes must be higher than those of existing applications, since most respondents pointed out that it was not sufficient to gain social acceptance and meet users' lifestyle, but it needed not be as high as ordinary garments. In the next stage, axial coding, all the categories were connected together through the use of a coding paradigm proposed by Strauss and Corbin (1990). The paradigm model clarifies the relations of a phenomenon, causal conditions, consequences, context, strategies that can be taken, and intervening conditions (see figure 6).

$\underset{\text { Causal }}{\text { conditions }} \rightarrow$ A phenomenon $\rightarrow$ Context $\rightarrow \begin{gathered}\text { Intervening } \\ \text { conditions }\end{gathered} \rightarrow \begin{gathered}\text { Action/interaction } \\ \text { strategies }\end{gathered} \rightarrow$ Consequence

\section{Paradigm Model}

Figure 6 Paradigm models (Strauss and Corbin, 1990)

The categories discovered in the open coding were analysed to find out the relationships and then linked together to present the results of the focus groups as shown in figure 7.

\section{Casual condition}

Smart Clothes need to gain social acceptance.

They must fulfil emotional requirements as all clothes do. $\downarrow$

\section{A phenomenon} Adding fashion values

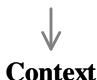

People wear clothes according to their mood They require the same electronic functions everyday.

\section{Intervening conditions}

Smart systems cannot be embedded in every garment Electronic parts have a longer lifecycle than the clothes'.

\section{Action/interaction strategies}

Allowing user to personalise function and style by turning electronic parts into accessories, e.g. zip or button.

\section{Consequence}

The idea can be achieved with current technology Conflict between fast trend and long lifecycle is solved.

\section{Casual condition}

Smart Clothes need to gain social acceptance. They must be more practical and commercial.

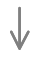

\section{A phenomenon}

Adding values from users' point of view

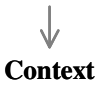

New functions must be worth for extra money. 'Smart' means doing what users want, not everything.

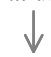

Intervening conditions

Applications must be easy to disassemble and dispose. New functions must be achieved by current technologies.

\section{Action/interaction strategies}

Providing functions that fit social trends, e.g. healthy lifestyle. Electronic parts must be customised and disassembled easily.

\section{Consequence}

Users may perceive Smart Clothes as a practical product. Users may be willing to pay extra for useful functions. 
According to the paradigm models in figure 6, it can be seen that all designers had concerns about social acceptance, commercialisation and current technological achievement. Both designers showed their interest in sportswear products. Nevertheless, the electronic features should not be limited to only this function. Electronic properties should also provide emotional value to the user and could be used purely for aesthetic reasons. Most respondents suggested that electronic functions should not be permanently fixed to the garment due to the benefits in terms of product lifecycle, customisation and disassembly. Nonetheless, this direction can be changed when all electronics are made of fabric and do not cause environmental problems. The results revealed that product design thinking and fashion design approaches could be reconciled. Considering the results of the questionnaire survey and the focus groups, figure 2 is subsequently revised and presented below.

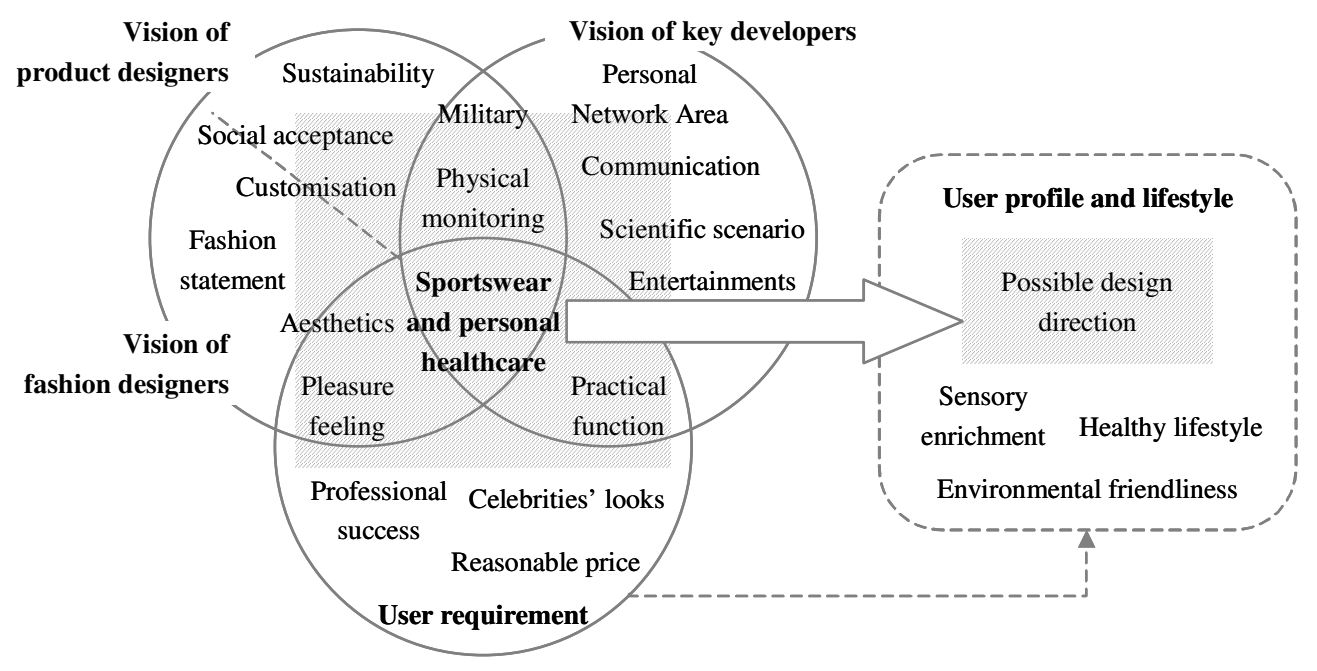

Figure 8 Diagram illustrating a design direction based on the visions of three stakeholders

\section{Conclusion}

The conclusion will be divided into three parts according to the aims of this research.

Firstly, a profile and user requirement of the target group is described. According to the choices of role models, favourite possessions and their personalities, it can be assumed that the target audiences are interested in sports, health, and their looks. Although, the targets choose the products according to their physical appearance, they also have concerns about the usability and price. Moreover, the products have to match and express their desirable lifestyle. As a result, expensive products without practical function are not suitable for this 
group. This confirms that changing from the technical approach to the user-centred one is the right direction. The research illustrated that there is a difference in the way electronic devices and fashion clothes are perceived, purchased and employed. However, it is possible to reconcile these differences because the criteria of both products include the same factors. It is noted that the position of sportswear on the spectrum of purchasing criteria is probably an appropriate place for Smart Clothes, since it stands in the middle of the spectrum, incorporating both functional and emotional values.

Secondly, the vision of future lifestyle of this group is identified. The questionnaire results reveal that consumers expect a better quality of life in terms of health and wellbeing. The targets are interested in how these products and technologies can improve their sensory experience. Moreover, they want environmentally friendly products and technologies.

Finally, the new design direction is specified. Based on the user's profile, requirements and their vision of future lifestyle, it can be assumed that sportswear and personal healthcare applications are the favourite choice since they match the personality and the lifestyle of the target audiences. In addition, this idea is supported by the key developers involved in Smart Clothing development from the interviews along with most of the focus group respondents. Since the users possibly required these functions everyday, it is not practical to have these electronic features permanently fixed on a particular garment. Many respondents suggested that electronic functions should act as basic 'accessories' of the clothes, such as a button or a zip does. Accordingly, the functions can be 'customised' in order to ensure that the technologies are useful and match the consumer's lifestyle and fashion trends. In order to do so, the electronic components should be self-contained and self-sufficient, and should not require further system support. Customisation encourages people to keep products for longer. This idea helps solve the conflict between long development time and fast movement in fashion. Smart Clothes should not only look like an ordinary garment but also work well when the embedded technology is not functioning. Moreover, electronic function of the embedded devices should be invisible and should not be intrusive to the user. 


\section{RE REFERENCE}

An, Y., et al, 2003. DigitAll, Design Management Journal, 14 (4), 52-57.

Ariyatum, B. and Holland, R., 2003. A Strategic Approach to New Product Development in Smart Clothing, Journal of the Asian Design International Conference, 1, 70.

Ariyatum, B., Holland, R. and Harrison, D., 2004. Benefits and Challenges of Collaboration in Smart Clothing Development, Proceeding of the $8^{\text {th }}$ International Design Conference Design 2004, 2, 697-704.

Baurley, S., 2003. Interactive and Experiential Design in Smart Textile Products and Applications, Proceeding of International Textile Design and Engineering Conference (INTEDEC): Fibrous Assemblies at the Design and Engineering Interface, Edinburgh, 22-

24 September 2003

Baxter, M., 1995. Product design: a practical guide to systematic methods of development of new products, Chapman \& Hall, London.

Braddock, S. E. and O'Mahony, M., 1998. Techno textiles: revolutionary fabrics for fashion and design, Thames and Hudson, London.

Broersma, M., 2002. Smart Clothing expected to take off, <http://marketwatchcnet.com.com/2102-1040_3-956696.html?tag=st.util.print> [Internet] CNET News, Available from: [Accessed 27 July, 2004]

CNN, 2004. Stereo sweatshirt to hit shelves, <http://edition.cnn.com/2004/TECH/ptech/ 11/11/stereo.sweatshirt.reut/index.html> [Internet] CNN Technology, Available from: [Accessed 12 November, 2004]

Dodson, S., 2003. Wear down opposition, <http://www.guardian.co.uk/print/ 0,3858,4668526-110837,00.html> [Internet] The Guardian, Available from: [Accessed 27 July 2004]

Dunne, L., Ashdown, S. and McDonald, E., 2002. Smart Systems: Wearable Integration of Intelligent Technology, Proceeding of International Centre of Excellence for Wearable Electronics and Smart Products Conference, Cottbus, Germany.

Edwards, C., 2003. Wearable Computing Struggles For Social Acceptance; Technology: the ultimate fashion item?, IEE Review, October, 24-25.

Flick, U., 2002. An Introduction to Qualitative Research, Sage Publication, London. 
Forman, D., 2001. Wearable Computing, Computer Buyer's Guide and Handbook, October, 25-36.

France Telecom, 2003. Wearable Communication, <http://www.studio-creatif.com/Gb/Vet/ VetFr.htm?x=1> [Internet] France Telecom, Available from: [Accessed 3 October 2003]

Gould, P., 2003. Textiles gain intelligence, Materials Today, October, 38-43.

Kroes, P., 2002. Design methodology and the nature of technical artefacts, Design Studies, $23,287-302$.

Lee, S. and Stead, L., 2001. Clothing contra crime: New Technologies \& Design for the Body, Lecture notes from research seminar, $4^{\text {th }}$ June 2001.

LUNAR Design, 2001. LUNAR Design wins Prize in Alias/Wavefront \& IBM Design Competition: "BLU" jacket concept earns prestigious honour, <http://www.lunar.com/ pressroom/pressrel/033001.html > [Internet] Available from: [Accessed 29 July 2003] Mann, S., 1996. Smart Clothing, <http://wearcam.org/smart_clothing/node1.html> [Internet] Available from: [Accessed 31 July, 2002] Marculescu, D., et al, 2003. Ready to Ware, IEEE Spectrum, October, 28-32.

Marzano, S., 2000. The quest for power, comfort and freedom, In Eves, D. et al ed., New nomads: An exploration of wearable electronics by Philips, 010 Publishers, Rotterdam, 4-9. Meoli, D. and May-Plumlee, T., 2002. Interactive Electronic Textile Development: A Review of Technologies, Journal of Textile and Apparel, Technology and Management, 2 (2), 1-12.

Momphard, D., 2004. Tech Review, Taipei Times, $11^{\text {th }}$ July 2004, 19.

Morgan, D. L., 1998. The Focus Group Guidebook: Focus Group Kit 1, Sage Publication, London.

Mori, A., 2002. Street fashion goes high-tech <http://www.japantoday.com/e/?content $=$ fashion $\&$ cat=designer\&id=30> [Internet $]$ Japan Today, Available from: [Accessed 28 July 2004]

O'Mahony, M., 2002. Cyborg: the man machine, Thames \& Hudson, London Orth, M., Post, R., and Cooper, E., 1998. Fabric Computing Interfaces, Proceedings of Conference on Human Factors in Computing Systems, Los Angeles, 18-23 April 1998 
Pantzar, M., 2000. Consumption as Work, Play and Art: Representation of the Consumer in Future Scenarios, Design Issues, 16 (3), 3-18.

Philips, 2000. Philips and Levi's create first wearable electronics garment $<$ http://www.research.philips.com/In...se.asp?1> [Internet], Philips, Available from: [Accessed: 04 January 2003]

Randell, C., 2001. Computerised clothing will benefit textile manufacturers, Technical Textiles International, 10 (7) September, <http://wearables.cs.bris.ac.uk/public/ paper/index.html> [Internet] Available from: [Accessed 18 January, 2002] Rantanen, J., et al, 2000. Smart Clothing for the Arctic Environment, Proceeding of the $4^{\text {th }}$ International Symposium on Wearable Computer (ISWC), Atlanta, Georgia, 18-21 October $2000,15-24$.

Seymour Powell Foresight, 2003. Trends: Overview, Seymour Powell Foresight, London. Strauss, A. and Corbin, J., 1990. Basics of Qualitative Research: Grounded Theory Procedures and Techniques, Sage Publication, London.

Uotila, M., et al, 2003. Methods and Models for Intelligent Garment Design', Proceeding of International Textile Design and Engineering Conference (INTEDEC): Fibrous Assemblies at the Design and Engineering Interface, Edinburgh, 22-24 September 2003

Van Heerden, C., Mama, J., and Eves, D., 2000. Wearable electronics, In Eves, D. et al ed., New nomads: An exploration of wearable electronics by Philips, 010 Publishers, Rotterdam, 14-22.

Van Langenhove, L. and Hertleer, C., 2003. Smart Clothing: A new life, Proceeding of International Textile Design and Engineering Conference (INTEDEC): Fibrous Assemblies at the Design and Engineering Interface, Edinburgh, 22-24 September 2003

Ward, J., 2001. Cold comfort yarn, New Design, 5, 32-33.

Zhang, X. X. and Tao, X. M., 2001. Smart textiles (1): Passive smart, Textile Asia, 32 (6), 45-49.

\section{Acknowledgement}

The researcher would like to thank Miss Tara Kazi for her genuine help on statistical analysis and interpretation, and all respondents of the questionnaire survey and focus group for their kind participation, and insightful information. 
This questionnaire is part of the PhD Design Research, Department of Design, Brunel University. All information obtained will be used for academic purpose only.

\section{Section 1 General Question}

\section{Age:}

$\square$ Under $20 \quad \square$ 21-25 years old $\square$ 26-30 years old $\square$ 31-35 years old $\quad \square$ Over 35

\section{Occupation:}

(If you are a student, please specify your subject area, e.g. finance, marketing, etc)

3. Personality: (Please choose only one box.)

$\square$ Fashion-conscious $\square$ Sporty/Health-concern $\square$ High tech

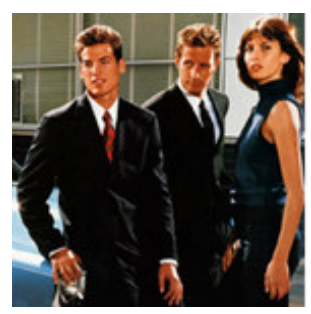

$\square$ Fun/Adventurous

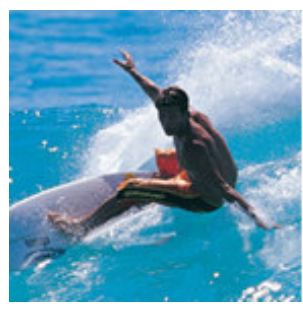

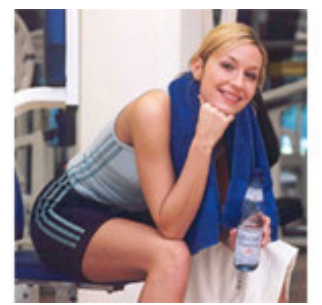

$\square$ Practical/Price-concern

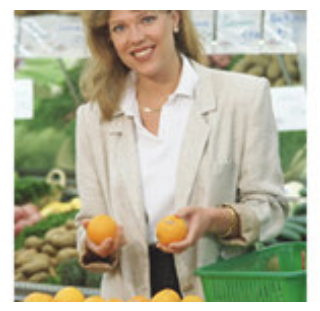

$\square$ Businessman
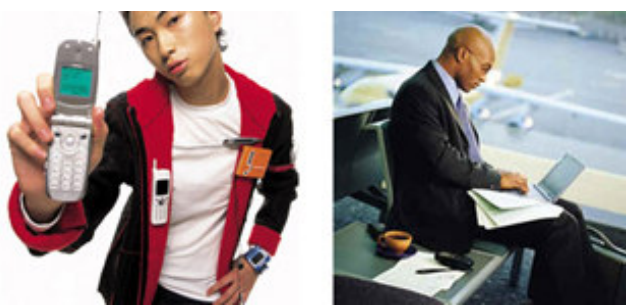

$\square$ Other.

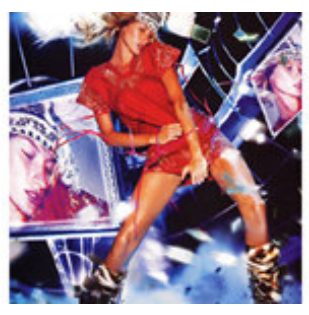

\section{Role model or favourite celebrity:}

(Please name your most favourite celebrity, top athlete, politician, or public person.)

5. The reason you choose this person as your role model: (Please choose only one box.)
$\square$ Physical appearance
$\square$ Personality
$\square$ Expertise
$\square$ Success
$\square$ Lifestyle
$\square$ Money \& Possession
$\square$ Fame
$\square$ Other 
6. What is your favourite object and why?

(Please name the most favourite object you possess and the reason.)

7. What is your most desired object and why?

(Please name the most desirable object you want to possess and the reason.)

\section{Section 2 Purchasing Criteria}

8. How often you buy mobile phone? (Please choose only one box.)

$\square$ Every time they launch new model $\square$ More than 2 times a year $\quad \square$ Once a year

$\square$ Every 2-3 years $\square$ When the old one is broken $\square$ Other.

9. Which mobile phone do you prefer? (Please choose only one box.)

$\square$ Samsung

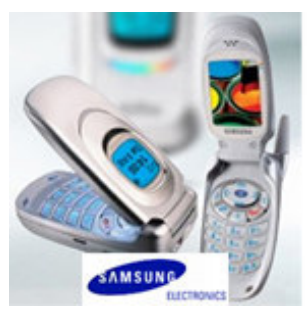

$\square$ Nokia

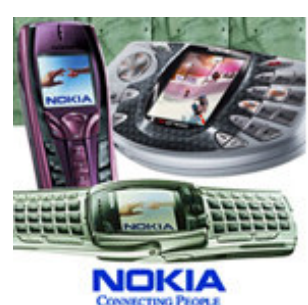

$\square$ Other $\square$ Panasonic

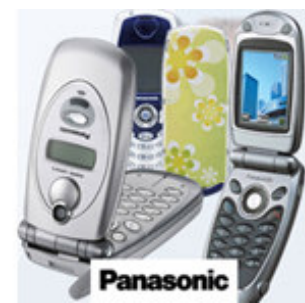

$\square$ Sharp

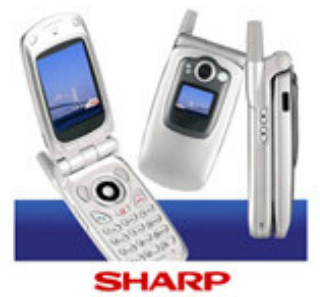

$\square$ Sony Ericsson

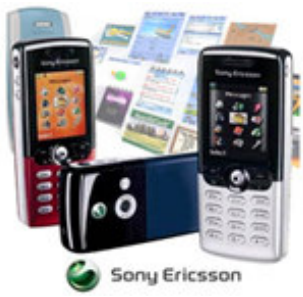

$\square$ Motorola

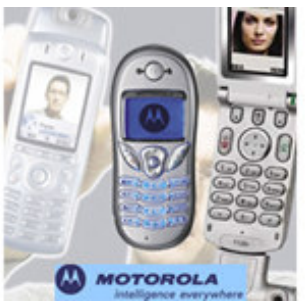

$\square$ Siemens

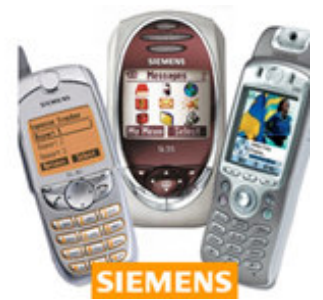

$\square$ NEC

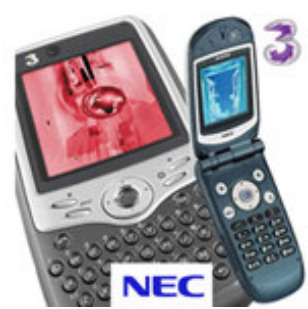

10. Criteria for mobile phone: (Please choose the most important reason - one only.)
$\square$ Good design
$\square$ Practical functions
$\square$ Newness \& Novelty
$\square$ Reliability
$\square$ Match your lifestyle
$\square$ Value for money
$\square$ Famous brand
$\square$ Technology \& Features
$\square$ Other. 
11. What is the most 'undesirable factor' that makes you reject particular mobile phone? (Please choose the most important reason - one only.)

$\begin{array}{lll}\square \text { Unattractive design } & \square \text { Bulky \& Heavy } & \square \text { Dated/old model } \\ \square \text { Difficult to use } & \square \text { Do not fit your lifestyle } & \square \text { Unreasonable price } \\ \square \text { Not famous brand } & \square \text { No new features } & \square \text { Other....................... }\end{array}$

12. How often you buy new clothes? (Please choose only one box.)

$\begin{array}{lll}\square \text { Every week } & \square \text { Every 2-3 weeks } & \square \text { Once a month } \\ \square \text { Once every 2-3 months } & \square \text { Every season } & \square \text { Less than } 4 \text { times a year } \\ \square \text { When the old one is worn out } & \square \text { Special occasion } & \square \text { Other........................................ }\end{array}$

13. Which fashion brand do you prefer? (Please choose only one brand.)

$\square$ DKNY $\quad$ Next $\square$ Topshop \& Topman $\square$ Marks \& Spencer
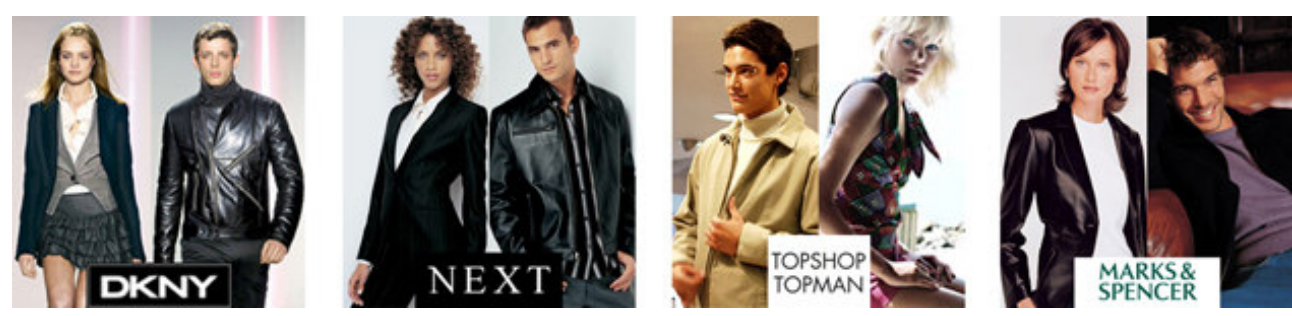

$\square$ Gap

$\square$ Matalan

$\square$ Versace

$\square \mathrm{H} \& \mathrm{M}$
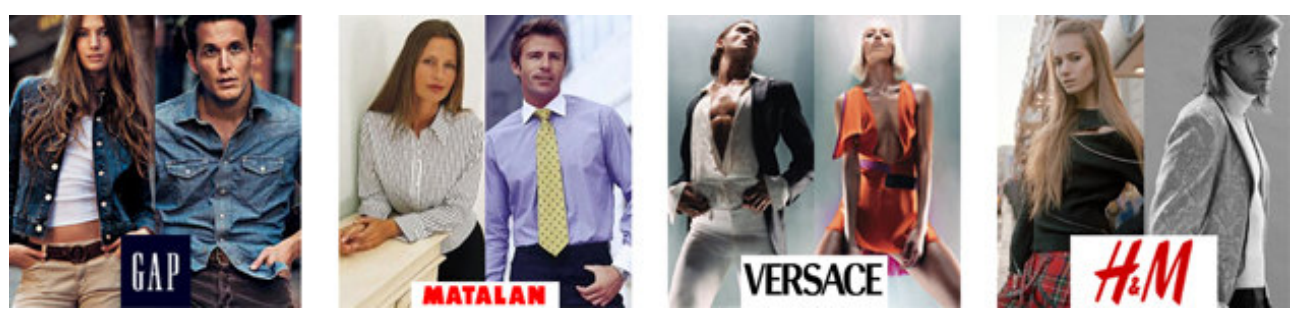

$\square$ Other

14. Criteria for clothes: (Please choose the most important reason - one only.)

$\square$ Good design $\quad \square$ Practical \& Easy to look after

$\square$ Newness \& Trendiness

$\square$ High quality

$\square$ Match your lifestyle \& personality

$\square$ Value for money

$\square$ Famous brand

$\square$ Suitable to wear in many occasions

$\square$ Other. 
15. What is the most 'undesirable factor' that makes you reject particular fashion

brand? (Please choose the most important reason - one only.)

$\square$ Unattractive design $\square$ Impractical \& Difficult to look after $\square$ Outdate or last-season style

$\square$ Low quality $\quad \square$ Do not fit your lifestyle $\quad \square$ Unreasonable price

$\square$ No-name brand $\quad \square$ Can be worn only limited occasions $\square$ Other.

16. Which sport brand do you prefer? (Please choose only one brand.)

$\square$ Reebok

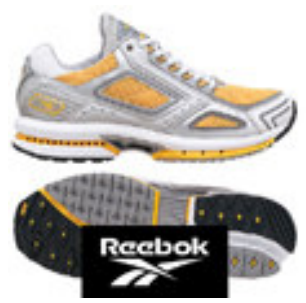

$\square$ Ellesse

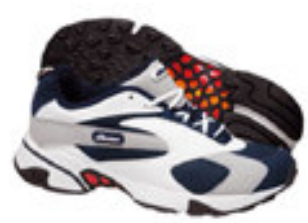

ellesse $\square$ Adidas

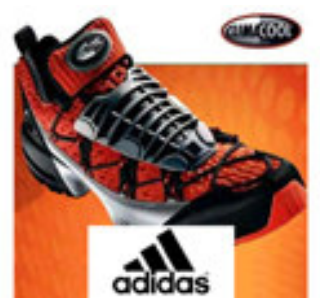

$\square$ Converse

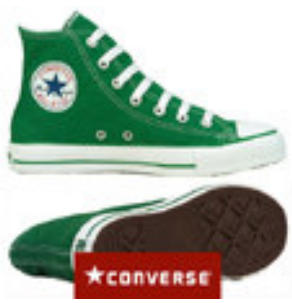

$\square$ Nike

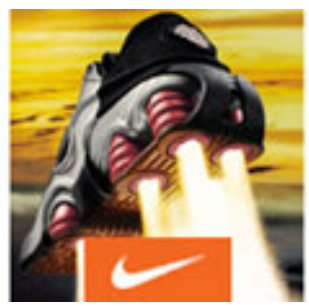

$\square$ Fila

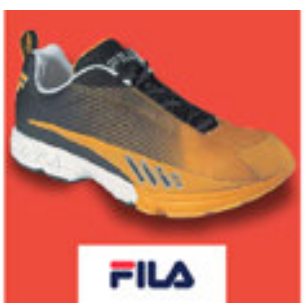

$\square$ Mizuno

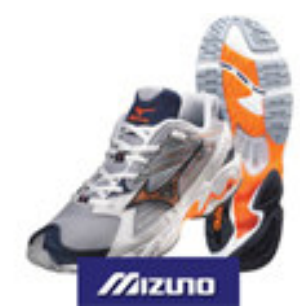

$\square$ Puma

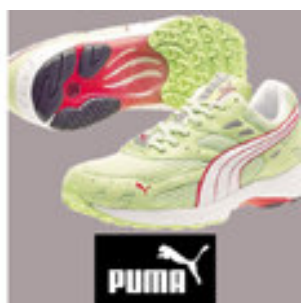

$\square$ Other

17. Criteria for sport shoes: (Please choose the most important reason - one only.)

\begin{tabular}{|c|c|c|}
\hline$\square$ Good design & $\square$ Practical functions & $\square$ Newness \& Trendiness \\
\hline$\square$ High quality & $\square$ Match your lifestyle & $\square$ Value for money \\
\hline$\square$ Famous brand & $\square$ Technology \& Feature & $\square$ Other... \\
\hline
\end{tabular}

\section{What is the most 'undesirable factor' that makes you reject particular sport}

shoes? (Please choose the most important reason - one only.)
$\square$ Unattractive design
$\square$ Impractical function
$\square$ Old-fashioned model
$\square$ Low quality
$\square$ Do not fit your lifestyle
$\square$ Unreasonable price
$\square$ No-name brand
$\square$ Outdate technology
$\square$ Other. 


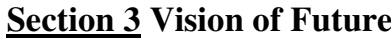

19. In your opinion, which one is considered 'desirable future'?

(Please choose only one box.)

$\square$ Avant-garde design $\square$ Robot/Gadget era $\square$ Environmental-friendly $\square$ Safety/Protection

(from crime/pollution)
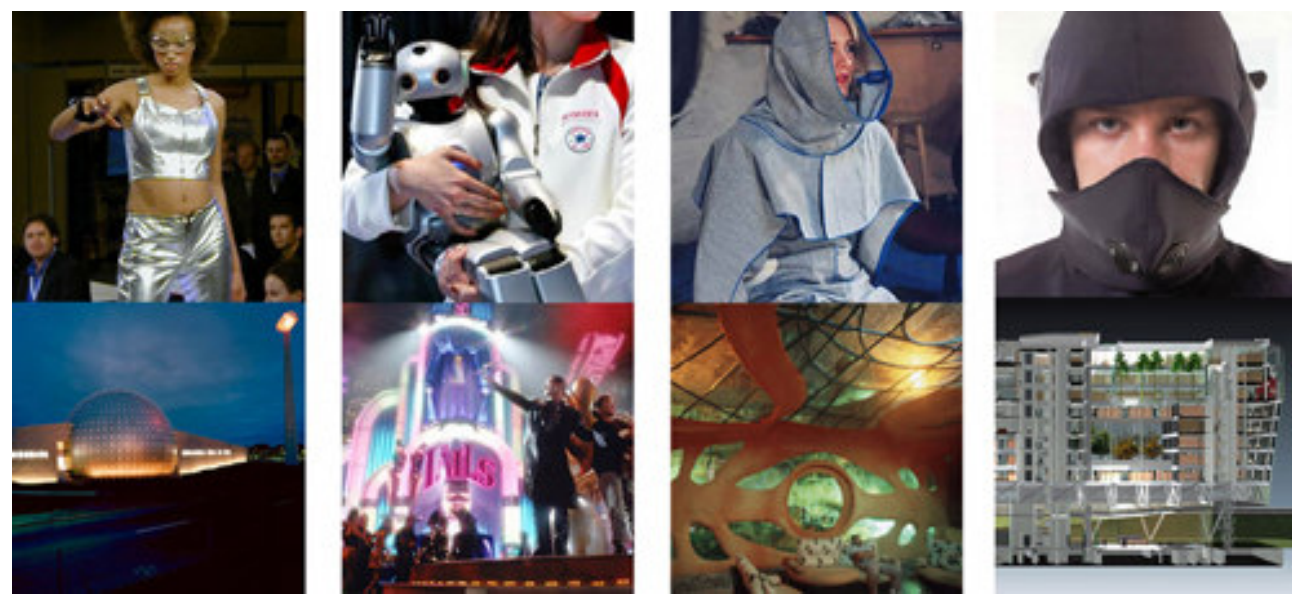

$\square$ Health/Quality of life $\square$ Computer/Network $\square$ Sensory Connect

\section{$\square$ Science fiction}

\& Communication
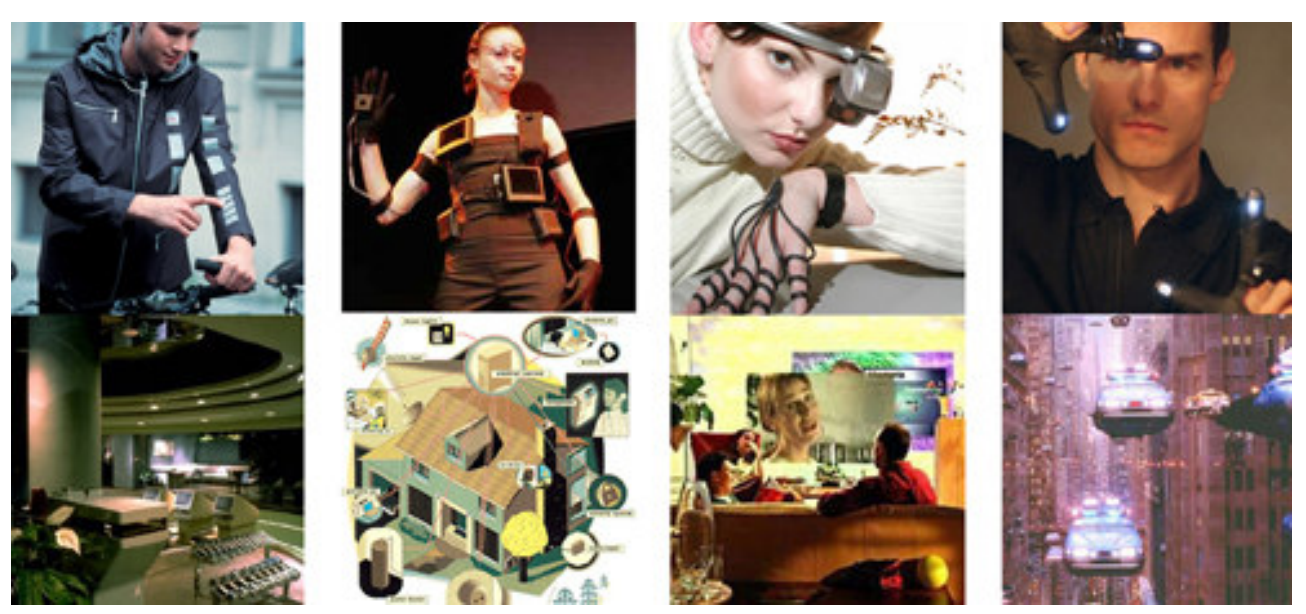

$\square$ Other.

Thank you very much for your time and co-operation,

Busayawan Ariyatum 